\title{
A Quick Guide on Electroporation
}

\author{
Jéssica Rodrigues da Silva ${ }^{1}$, Raul Guedert ${ }^{1}$, Marcelo Monte Mor Rangel ${ }^{2}$ and Daniela Ota Hisayasu Suzuki*1 \\ ${ }^{1}$ Department of Biomedical Engineering, Brazil
}

${ }^{2}$ Department of Veterinary Cancer, Brazil

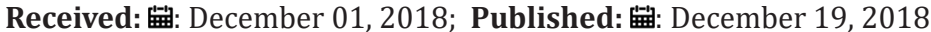

*Corresponding author: Daniela Ota Hisayasu Suzuki, IEB/UFSC, Universidade Federal de Santa Catarina, SC, Brazil

\author{
Abstract \\ Electroporation is a phenomenon that can increase the cells permeability and electrical conductivity due to applied electrical field pulses. \\ Electroporation are used to some medical applications, as cancer treatment and sterilization. This review brings electroporation improvements for \\ medical applications.
}

Keywords: Electroporation; Electrochemotherapy; Genetic Transfer; Tissue Ablation; Sterilization

\section{Introduction}

Electroporation is a physical phenomenon resulting from transient changes in the permeability and electrical conductivity in the plasma and nuclear membranes of a cell. The phenomenon occurs when a pulse with short time and high electrical field is applied in cells or tissue. An accumulation of charges due to ions migration occurs when the electric field is being applied, the cell membrane undergoes a rearrangement in their morphology after exceeding a critical threshold [1]. Therefore, the membrane presents pores formations. These pores are large enough to transport molecules and ions [2].

There are three different types of Electroporation due to exposing time and electric field intensity while the pulse application. Firstly, Reversible Electroporation (RE) occurs when the electric field is high enough to exceed the critical threshold, but the cell is still able to return to their initial state. Secondly, Irreversible Electroporation (IRE) occurs when the electric field is extremely high, and the number of pores created induce the cell osmotic imbalance or homeostasis loss, resulting in cell death. A third type of electroporation is defined when the electric field intensity or exposing time are so high that Joule heating is observed (Thermal Irreversible Electroporation) [3]. Due to benefits of non-thermal solutions in biomedical applications, Reversible and Irreversible Electroporation are the main studied types.

\section{Applications}

Since the differences between the Electroporation types, the applications are divided due to their main effect.

\section{Reversible Electroporation (RE)}

As the cell is not destroyed in Reversible Electroporation process, it can be used to insert molecules in intracellular environment.

Electrochemotherapy (ECT): Introduce drugs into the intracellular environment is the one of the greatest difficulties of chemotherapy treatments. This implies in high doses of medicine for a long time to ensure that all tumor cells are reached, increasing the side effects [4]. RE can accelerate this process by increasing membrane permeability of the tumor tissue. ECT protocol is defined by European Standard Operating Procedures of Electrochemotherapy (ESOPE) published in 2006 [5]. Currently, ECT is used for treatment of cutaneous and subcutaneous tumors in European clinics [6,7] and in veterinary clinics in Brazil [8]. Studies are now focused on extending treatment for deep tumors [9] besides ensuring the success of tumor RE through bioimpedance analysis [10]. IRE can also be observed as a side effect in ECT treatment. This is not a problem since the tissue affected by IRE will eventually die.

Genetic Transfer: The need to perform DNA transfer through two physical barriers to reach the cell nucleus has attracted interest on RE use to introducing plasmids into the cell nucleus. This technique has emerged as a promising gene delivery method mainly thanks to it is low cost, easiness of realization and safety in production and utilization. Therefore, this method can be considered the non-viral method that presents greater efficiency of gene transfer [11]. 


\section{Irreversible Electroporation (IRE)}

The main advantage of IRE is to destroy cells without causing thermal effects. Therefore, it is used in applications that require the death of diseased tissues or other microorganisms.

Non-thermal Tissue Ablation: Tissue Ablation may be necessary in some cancer cases. Different from techniques like Radiotherapy and Cryoablation, IRE can perform tissue ablation without thermal issues. Temperature variations can be harmful to healthy tissues and organs close to tissues that must be destroyed. As well as ECT, it is necessary ensure the success of tumor IRE and studies are being performed on bioimpedance analysis [10].

Non-thermal Sterilization: Food and water sterilization have been researched for a long time. The need to preserve food outside the production season and the treatment of drink water is constant. Traditional process like Pasteurization can change colour, smell, texture, flavour and nutritional value due to thermal effects. Use of IRE can kill microorganisms without affecting the product properties. Researches on the molecular mechanism of IRE and developing systems to ensure complete IRE sterilization are the main future challenges [12].

\section{Conclusion}

Electroporation main applications has been described. The use of electroporation results in currently highly relevant medical applications, such as cancer treatment and gene transfer. The number of studies being performed indicate that the technique is continuously evolving.

\section{References}

1. Miklavcic, Damijan, Leila T (2010) Numerical study of the electroporation pulse shape effect on molecular uptake of biological cells. Radiol Oncol 44(1): 34-41

\section{ISSN: 2574-1241}

DOI: $10.26717 / B J S T R .2018 .12 .002248$

Daniela Ota Hisayasu Suzuki. Biomed J Sci \& Tech Res

(C) (P) This work is licensed under Creative Commons Attribution 4.0 License

Submission Link: https://biomedres.us/submit-manuscript.php
2. Daniela OHS, Airton R, Maria CMR, Luisa HC, Fátima RMBS, et al. (2011) Theoretical and experimental analysis of electroporated membrane conductance in cell suspension. IEEE Trans Biomed Eng 58(12): 33103318.

3. Davalos R, Mir LM, Rubinsky B (2005) Tissue ablation with irreversible electroporation. Ann Biomed Eng 33(2): 223-231.

4. Sersa G, Cemazar M, Snoj M (2009) Electrochemotherapy of tumours. Curr Oncol 16(2): 34-35.

5. Mir LM, Gehl J, Sersa G (2006) Standard operating procedures of the electrochemotherapy: Instructions for the use of bleomycin or cisplatin administered either systemically or locally and electric pulses delivered by the Clinipo-ratorTM by means of invasive or non-invasive electrodes. Eur J Cancer Suppl 4(11): 14-25

6. Pucihar G, Mir L, Miklavčič D (2002) The effect of pulse repetition frequency on the uptake into electropermeabilized cells in vitro with possible applications in electrochemotherapy. Bioelectrochemistry 57(2): 167-172.

7. Calvet CY, Famin D, André FM, Mir LM (2014) Electrochemotherapy with bleomycin induces hallmarks of immunogenic cell death in murine colon cancer cells. Oncoimmunology 3: 28131.

8. Suzuki DOH, Berkenbrock JA, de Oliveira KD, Freytag JO (2017) Rangel MMM Novel application for electrochemotherapy: Immersion of nasal cavity in dog. Artif Organs 41(8): 767-773.

9. Miklavcic D, Snoj M, Zupanic A, Kos B, Cemazar M, et al. (2010) Towards treatment planning and treatment of deep-seated solid tumors by electrochemotherapy. Biomed Eng Online 9:10.

10. Neal II, Robert E, Robertson JL, Davalos RV (2012) Experimental characterization and numerical modeling of tissue electrical conductivity during pulsed electric fields for irreversible electroporation treatment planning. IEEE Trans Biomed Eng 59(4): 1076-1085.

11. Bloquel C, Fabre E, Bureau MF, Scherman D (2004) Plasmid DNA electrotransfer for intracellular and secreted proteins expression: New methodological developments and applications. J Gene Med 6: 11-23.

12. Golberg A, Fischer J, Rubinsky B (2009) The use of irreversible electroporation in food preservation. pp. 273-312.

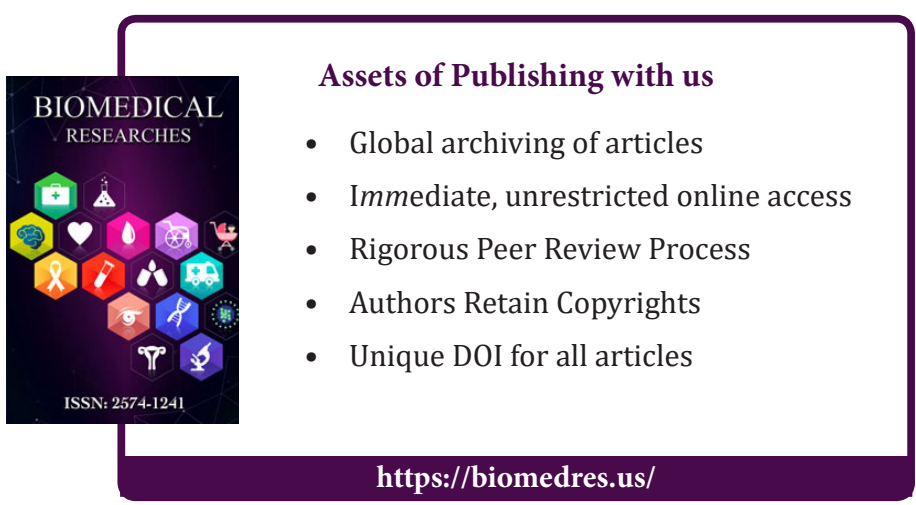

